\title{
Measurements and quality control of ammonia eddy covariance fluxes: a new strategy for high-frequency attenuation correction
}

\author{
Alexander Moravek et al. \\ Correspondence to: Alexander Moravek (amoravek@yorku.ca)
}

The copyright of individual parts of the supplement might differ from the CC BY 4.0 License. 


\section{WindTrax simulation}

The range of possible $\mathrm{NH}_{3}$ fluxes during the peak emission periods after fertilization was investigated using WindTrax (Thunder Beach Scientific, Canada). WindTrax uses backward Lagrangian Stochastic (bLS) modelling to inferred flux

5 estimates based on the measured trace gas mixing ratios and information on the turbulent transport. For the approach, the background mixing ratio has to be known and the source area (in case of emission) has to be defined.

As input we used the $\mathrm{NH}_{3}$ mixing ratio measured by the QCL and the turbulence statistics by the CSAT3 sonic anemometer at $2.5 \mathrm{~m}$ a.g.l. For practicability reasons, we defined the $\mathrm{NH}_{3}$ source area as a circle with $500 \mathrm{~m}$ diameter centred at the measurement location, which approximately represents the average extent of the agricultural field in each wind direction.

10 Since no background $\mathrm{NH}_{3}$ measurements were made, which are needed for the flux calculation with WindTrax, we used in different scenarios a $\mathrm{NH}_{3}$ background mixing ratio between 0 and 4 ppbv. For the analysis, we focused on two days with the highest emission fluxes, 28 and 30 May 2017 (8:00 - 16:00 EST), where the background $\mathrm{NH}_{3}$ would be expected to have less influence on the $\mathrm{NH}_{3}$ mixing ratio from QCL than during other conditions.

As shown in Fig. S1, on $28 \mathrm{May} \mathrm{NH}_{3}$ mixing ratios ranged from 2.7 to $10.2 \mathrm{ppbv}$, with the peak mixing ratio measured at

15 10:30 EST. At that time also the highest $\mathrm{NH}_{3}$ emission flux of $753 \mathrm{ng} \mathrm{m}^{-2} \mathrm{~s}^{-1}$ was observed, indicating that a significant fraction of the measured $\mathrm{NH}_{3}$ mixing ratio is linked to the emission from the fertilized corn field. Assuming a background mixing ratio of 2 ppbv, which seems a realistic background value given the nighttime $\mathrm{NH}_{3}$ mixing ratios of about 2 ppbv during that period, the modelled flux using WindTrax is with $829 \mathrm{ng} \mathrm{m}^{-2} \mathrm{~s}^{-1}$ very close to the measured $\mathrm{NH}_{3}$ flux. Assuming a background mixing ratio of 0 ppbv, which represents the upper limit of possible $\mathrm{NH}_{3}$ emissions modelled with WindTrax, yields an emission flux

20 of $1034 \mathrm{ng} \mathrm{m}^{-2} \mathrm{~s}^{-1}$ at that time. The $30 \mathrm{~min}$ periods before and after the peak show the best match between modelled and measured $\mathrm{NH}_{3}$ fluxes for $\mathrm{NH}_{3}$ backgrounds between 2 and 4 ppbv.

On 30 May, the prevailing $\mathrm{NH}_{3}$ mixing ratios were lower and steadily between 2 and 3 ppbv. Still, the second highest $\mathrm{NH}_{3}$ emission after fertilizer application was observed on that day, with a peak emission of $190 \mathrm{ng} \mathrm{m}^{-2} \mathrm{~s}^{-1}$ at 14:00 EST. This emission flux matches well with the modelled $\mathrm{NH}_{3}$ flux of $193 \mathrm{ng} \mathrm{m}^{-2} \mathrm{~s}^{-1}$ using a background of 1 ppbv. Under a background scenario of $0 \mathrm{ppbv}$, the maximal emission from WindTrax at that time period is $295 \mathrm{ng} \mathrm{m}^{-2} \mathrm{~s}^{-1}$, which is 1.5 times larger than the measured flux.

The analysis with WindTrax, using the two days with the highest $\mathrm{NH}_{3}$ emissions after fertilization, shows that the expected fluxes are in the range of the measured $\mathrm{NH}_{3}$ fluxes during those periods. During the peak emissions on both days, the maximal WindTrax emission estimates are about 1.5 times higher than the fluxes measured by the eddy covariance system. Since no

30 background measurements outside of the corn field domain are available, WindTrax could not be used for other periods of the dataset, where the $\mathrm{NH}_{3}$ emission fluxes were smaller or even deposition was measured. 
(a)

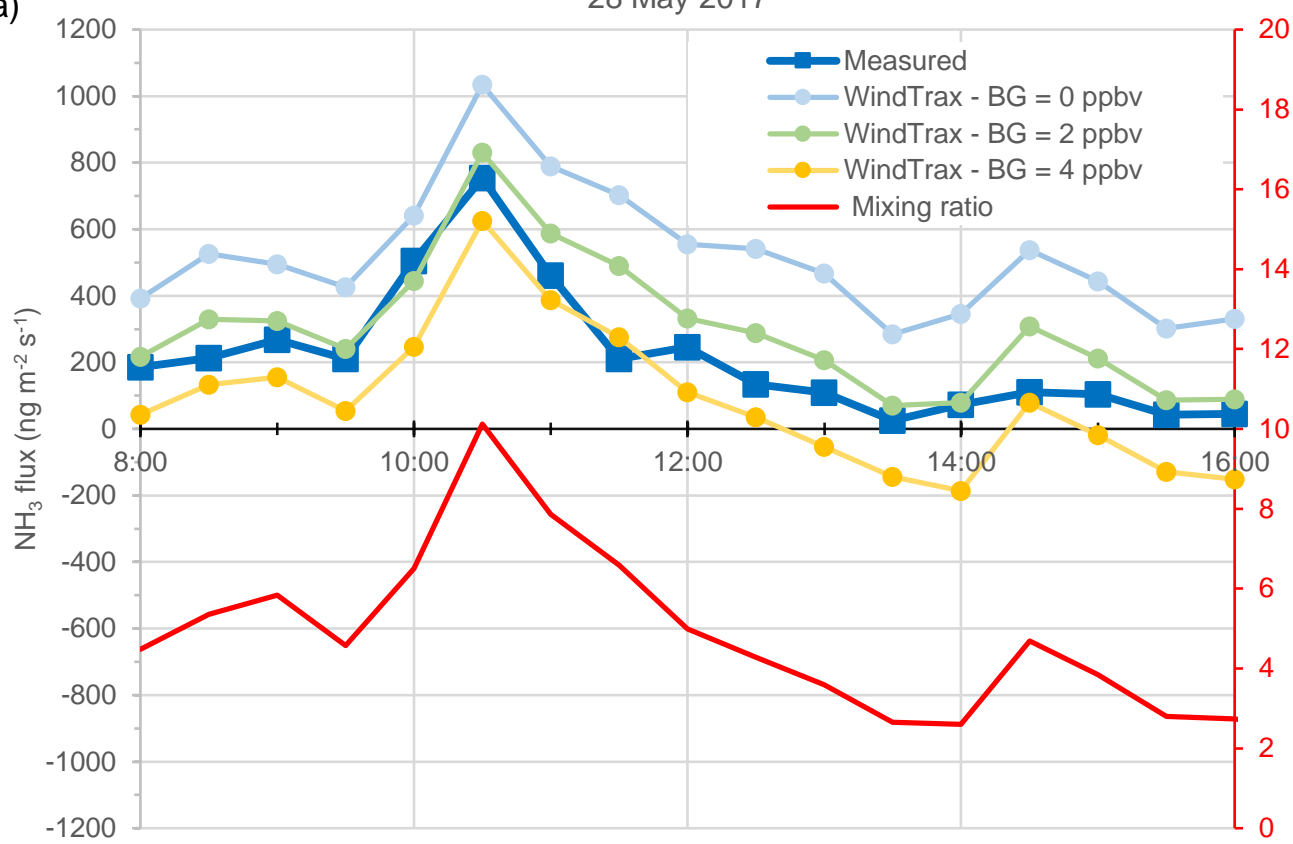

(b)

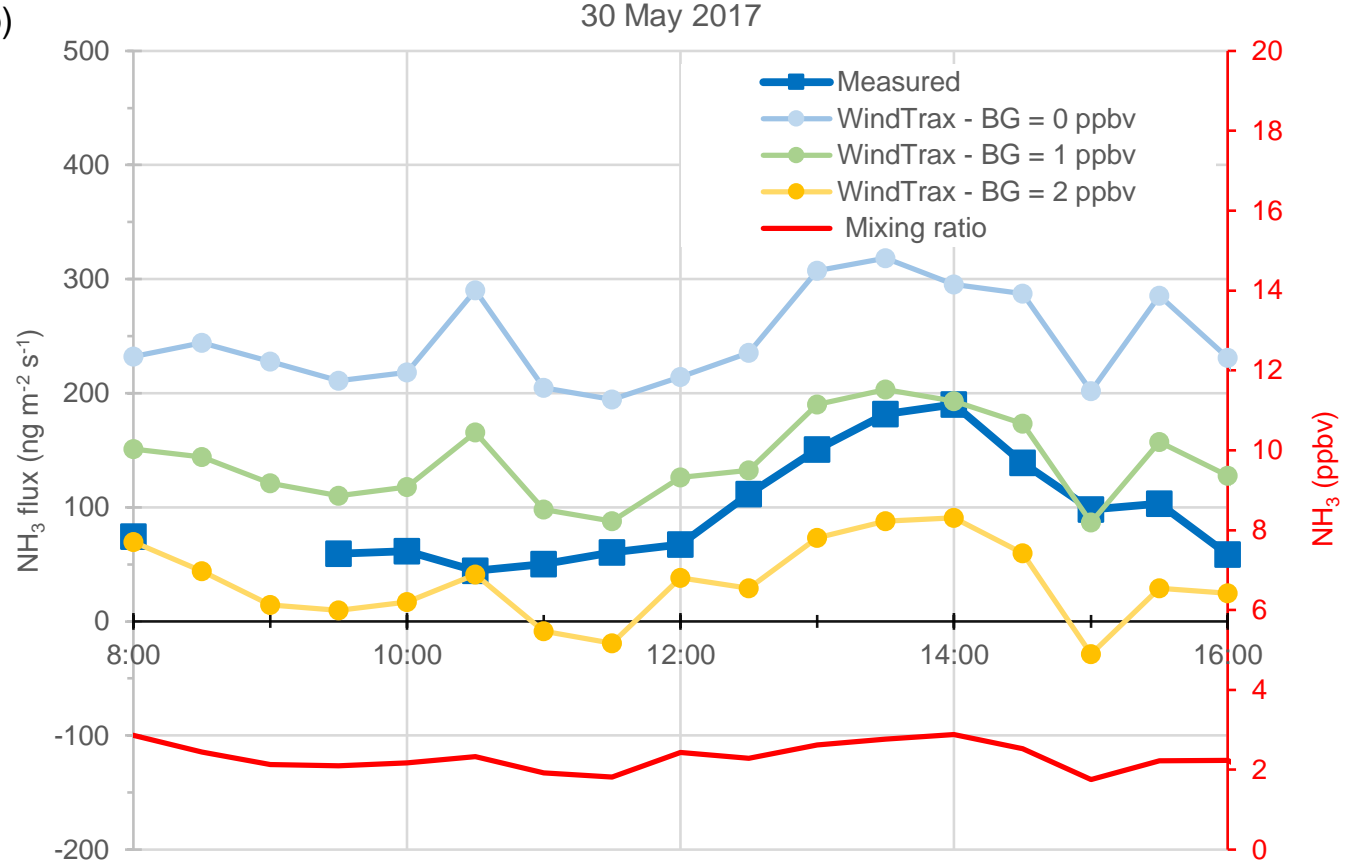

Figure S1: Estimated $\mathrm{NH}_{3}$ fluxes (left $\mathrm{y}$-axis) from the corn field using the WindTrax dispersion model. Shown are the daytime (8:00 5 to 16:00 EST) periods of (a) 28 May and (b) 30 May 2017, which were the periods when the highest $\mathrm{NH}_{3}$ fluxes were measured. For the model estimates, scenarios with background $\mathrm{NH}_{3}$ mixing ratios ranging from 0 to 4 ppbv were used together with the measured $\mathrm{NH}_{3}$ mixing ratios (right $\mathrm{y}$-axis). The measured eddy covariance fluxes, to which the results from the WindTrax model are compared, include the high frequency attenuation correction using the time response method. 